\title{
Evaluation of Loess Capability for Adsorption of Total Nitrogen (T-N) and Total Phosphorous (T-P) in Aqueous Solution
}

\author{
Daeik Kim, ${ }^{\dagger}$ Keon Sang Ryoo, ${ }^{*}$ Yong Pyo Hong, and Jong-Ha Choi \\ Department of Applied Chemistry, Andong National University, Andong 760-749, Korea. ${ }^{*}$ E-mail: ksr@andong.ac.kr \\ ${ }^{\dagger}$ School of Electrical, Electronic Communication, and Computer Engineering, Chonnam National University, \\ Yeosu 550-749, Korea \\ Received April 7, 2014, Accepted April 29, 2014
}

\begin{abstract}
The aim of the present study is to explore the possibility of utilizing loess for the adsorption of total phosphorous (T-P) and total nitrogen (T-N) in water. Batch adsorption studies were performed to evaluate the influences of various factors like initial concentration, contact time and temperature on the adsorption of T-P and T-N. The adsorption data showed that loess is not effective for the adsorption of T-N. However, loess exhibited much higher adsorption capacity for T-P. At concentration of $1.0 \mathrm{mg} \mathrm{L}^{-1}$, approximately $97 \%$ of T$\mathrm{P}$ adsorption was achieved by loess. The equilibrium data were fitted well to the Langmuir isotherm model. The pseudo-second-order kinetic model appeared to be the better-fitting model because it has higher $R^{2}$ compared with the pseudo-first-order and intra-particle kinetic model. The theoretical adsorption equilibrium $q_{e, c a l}$ from pseudo-second-order kinetic model was relatively similar to the experimental adsorption equilibrium $q_{e, e x p}$. The thermodynamic parameters such as free energy $\Delta G$, the enthalpy $\Delta H$ and the entropy $\Delta S$ were also calculated.
\end{abstract}

Key Words : T-P, T-N, Loess, Adsorption, Isotherm

\section{Introduction}

Nitrogen and phosphorous have aroused considerable public concern because of their increased discharge into water bodies including reservoirs, lakes, streams and rivers. They are essential elements necessary for all living cells as a component of cell membranes. However, their enrichment in water bodies leads to the algal blooms. The high growth of algae in aquatic system adversely affects the water quality. There have been a lot of studies on the removal of nitrogen and phosphorous from wastewater using biological and chemical methods. ${ }^{1-6}$

Biological methods have not shown stable and sufficient efficiencies in removing nitrogen and phosphorous from wastewater. Moreover, they have considerable difficulty in controlling microorganism due to the long-term biodegradation. Chemical methods have been widely used as a viable alternative to biological methods. Nevertheless, their applicability of wastewater treatment is limited in terms of the high cost of chemical additives and the production of chemical sludge.

Among the various methods of wastewater treatment, adsorption is a quite popular method due to the simplicity and the absence of sludge, as well as the availability of a wide range of adsorbents..$^{7-9}$ Activated carbon has become a favorite choice for removal of pollutants from wastewater because of its high surface area and pore volume, along with convenient regeneration of spent carbon. However, the high cost of activated carbon makes its use limited. Therefore, many studies have described the adsorption abilities of various low-cost adsorbents as the potential replacement. Of all low-cost adsorbents, loess may be a good candidate as an adsorbent because it is environmentally friendly and can be easily obtained across the nation.

Over several ten million years, Korean loess has been transported from arid areas in China and Mongolia by the wind and deposited at mountain regions near the coast. Especially, Gyeongju, Goseong, Sanchung and Hamyang are regions that covered by thick loess stacks. In recent years, the adsorptive capability of loess for organic pollutants and metal ions has been reported by several literatures. Also, loess has been studied on removal of total phosphorous or phosphate from municipal wastewater, including natural adsorbents such as calcite, alunite, wollastonite, dolomite and kaolinite. ${ }^{10-15}$ The major components of loess are composed of alumina oxide, silica oxide, iron oxide, calcium oxide and residual carbon. However, the constituents of loess vary in different localities. Therefore, further research on adsorption capacity and characteristics of loess are needed to be carried out.

The aim of the present study is to explore the possibility of utilizing loess for the adsorptive removal of T-N and T-P from aqueous solution. The effect of factors such as contact time, initial concentration and temperature was systematically investigated. Experimental equilibrium data were fitted to the Freundlich and Langmuir isotherm models to determine the best-fit isotherm equation. The kinetics of T-N and T-P adsorption on loess was analyzed by fitting pseudo-firstorder, pseudo-second-order and intra-particle diffusion kinetic models. In addition, thermodynamic parameters such as the change in Gibbs free energy $\Delta G$, the enthalpy $\Delta H$ and the entropy $\Delta S$ were also estimated to study the feasibility of the 
adsorption process.

\section{Materials and Methods}

Materials. Loess was taken from a suburban area of Gyeongju in Korea. To maintain a uniform particle size, loess was sieved through a 40 mesh sieve mechanically. The sieved loess particles were used without any kind of chemical modification. Loess was washed with ultrapure water for 24 $\mathrm{h}$ to remove dust and fine particulate matter, and then was dried overnight at $105{ }^{\circ} \mathrm{C}$ before use. The $\mathrm{N}$ and $\mathrm{P}$ stock solutions were prepared by dissolving the $\mathrm{N}$ and $\mathrm{P}$ standard solutions (Kanto Chemical Co., Inc, Japan) into distilled water.

Adsorption Studies. Adsorption studies were carried out by the batch system to obtain the rate and the equilibrium data. For these studies, a series of $250 \mathrm{~mL}$ flasks were employed. Each flask was filled with $100 \mathrm{~mL}$ of T-N and T-P solutions and kept in a thermostatic shaker. A known amount of loess was added into flasks and agitated at $200 \mathrm{rpm}$ for the desired time periods. The adsorption properties of loess were evaluated by varying different factors such as initial concentrations, contact time and temperatures. The initial concentrations of T-N and T-P in solution were in the range of 1.0 to $10.0 \mathrm{mg} \mathrm{L}^{-1}$. Contact time was ranged from 1 to $24 \mathrm{~h}$. The temperatures were operated at 278, 298 and $323 \mathrm{~K}$. At given time intervals, a fraction of the aqueous solution was withdrawn from the flasks. Subsequently, the solution was filtered and centrifuged to separate adsorbent. After centrifugation, the residual concentrations of T-N and T-P in the solution were determined by a UV/Visible spectrophotometer (S-3150, Scinco, USA) at the corresponding $\lambda_{\max }=220$ and $880 \mathrm{~nm}$, respectively.

Analysis. The element compositions of loess were analyzed with a X-ray Florescence Spectrometer (ZSX Primus II, Rigaku, Japan). Their specific surface area and pore volume were determined by $\mathrm{N}_{2}$ adsorption and desorption at $77 \mathrm{~K}$ using a Specific Surface Area Analyzer (ASAP-2010, Micromeritics, USA). The BET surface area was obtained by applying the Brunauer-Emmett-Teller (BET) equation to the adsorption data.

\section{Results and Discussion}

Characterization of Loess. The composition and physicochemical properties of loess were given in Table 1 . As seen in Table 1, most of chemical compounds in loess were silica, alumina and iron oxides along with calcium and potassium oxides as minor. The BET surface area of loess was determined as $40.72 \mathrm{~m}^{2} \mathrm{~g}^{-1}$ and its pore volume was found to be $0.092 \mathrm{~m}^{3} \mathrm{~g}^{-1}$.

Effect of Contact Time and Initial T-P and T-N Concentration. The batch adsorption studies were carried out with different initial T-P and T-N concentrations in the range of $1.0-10.0 \mathrm{mg} \mathrm{L}^{-1}$ while maintaining $0.25 \mathrm{~g}$ of loess. Figure 1 represents the adsorption capacity of loess for initial T-P and T-N (data not shown here) concentrations plotted as a
Table 1. Composition and physicochemical property of loess in Korea

\begin{tabular}{lcc}
\hline & & Mass (\%) \\
\cline { 2 - 3 } & $\mathrm{SiO}_{2}$ & 50.5 \\
& $\mathrm{Al}_{2} \mathrm{O}_{3}$ & 39.8 \\
& $\mathrm{Fe}_{2} \mathrm{O}_{3}$ & 5.73 \\
& $\mathrm{TiO}_{2}$ & 0.50 \\
& $\mathrm{Na}_{2} \mathrm{O}$ & 0.16 \\
& $\mathrm{CaO}$ & 0.91 \\
& $\mathrm{MgO}$ & 0.53 \\
& $\mathrm{~K}_{2} \mathrm{O}$ & 0.83 \\
BET surface area $\left(\mathrm{m}^{2} \mathrm{~g}^{-1}\right)$ & $\mathrm{SO}_{3}$ & 0.08 \\
Micropore surface area $\left(\mathrm{m}^{2} \mathrm{~g}^{-1}\right)$ & & 40.72 \\
External surface area $\left(\mathrm{m}^{2} \mathrm{~g}^{-1}\right)$ & & 5.07 \\
Pore volume $\left(\mathrm{m}^{3} \mathrm{~g}^{-1}\right)$ & & 35.65 \\
Micropore volume $\left(\mathrm{m}^{3} \mathrm{~g}^{-1}\right)$ & & 0.09 \\
Average pore diameter $(\mathrm{nm})$ & & 0.002 \\
pH & & 9.03 \\
\hline
\end{tabular}

function of contact time. Loess exhibited different adsorption capacity for T-P and T-N. The adsorption of T-P on loess was found within contact time. Whereas, the adsorption of T-N was not observed during the contact time, regardless of initial concentrations. As a result, it indicates that loess cannot play a crucial role as an adsorbent for adsorption of $\mathrm{T}-\mathrm{N}$ in aqueous solution.

As shown in Figure 1, adsorption amounts of T-P increased remarkably at the beginning of contact time. Thereafter, the adsorption decreased gradually and reached equilibrium in $1440 \mathrm{~min}$. The contact time corresponding to the maximum adsorption was considered as the equilibrium adsorption time. After equilibrium, the remaining concentrations of T-P in solution remained constant. The adsorption of T-P on loess was highly concentration dependent. The adsorption percentage was found to be lower with increasing initial T-P concentration. On the basis of initial concentrations, roughly $15-97 \%$ of T-P adsorption at equilibrium was achieved by

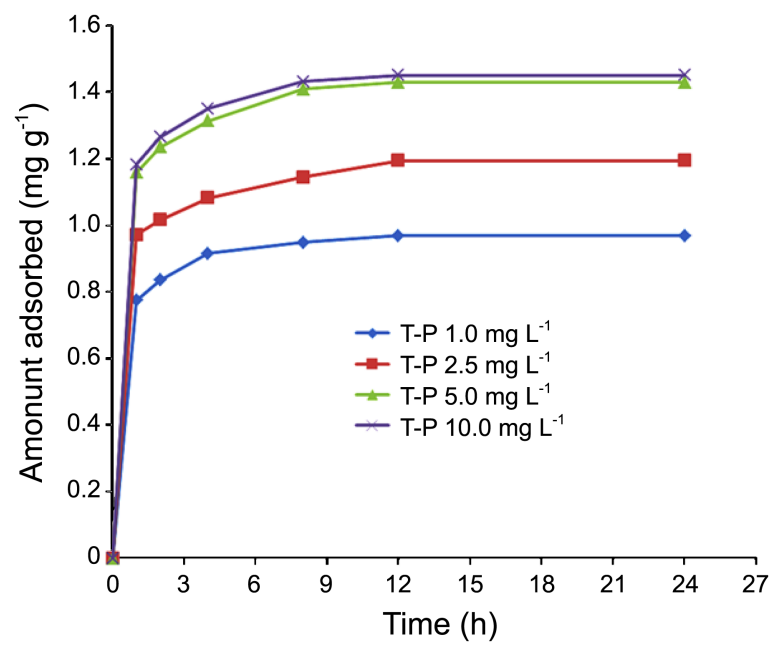

Figure 1. Adsorption of T-P and T-N on loess at 298 K. 
loess.

Adsorption Isotherm. Two widely used isotherm models, Freundlich and Langmuir isotherms, were employed to investigate the adsorption characteristics. Adsorption isotherms characterize the distribution of adsorbates between adsorbent and solution when adsorption equilibrium is reached at a constant temperature and provide parameters for designing and optimizing the adsorption batch system.

The Freundlich isotherm, which is an empirical equation for multi-layer adsorption of adsorbate onto heterogeneous surfaces, ${ }^{16}$ is expressed as:

$$
q_{e}=k_{f}\left(c_{e}\right)^{\frac{1}{n}}
$$

Where, $q_{e}\left(\mathrm{mg} \mathrm{g}^{-1}\right)$ is the amount of adsorbate adsorbed by adsorbent at equilibrium and $c_{e}\left(\mathrm{mg} \mathrm{L}^{-1}\right)$ is the equilibrium concentration of adsorbate in solution. The $k_{f}$ is the Freundlich constant related to adsorption capacity. The $1 / n$ is a measure of the adsorbent affinity for the adsorbate or surface heterogeneity, becoming more heterogeneous as its value gets closer to 0 . For linearization of the data, the Freundlich equation is written in logarithmic form:

$$
\log q_{e}=\log k_{f}+\frac{1}{n} \log c_{e}
$$

A linear plot of $\log q_{e}$ versus $\log c_{e}$ yields a slope $1 / n$ and an intercept of $\log k_{f}$.

The Langmuir isotherm model describes mono-layer adsorption on homogeneous surface with no interaction between adjacent adsorbed adsorbates. ${ }^{17}$ The Langmuir isotherm is written as:

$$
\frac{c_{e}}{q_{e}}=\frac{1}{Q_{b}}+\frac{c_{e}}{Q_{b}}
$$

Where, $Q\left(\mathrm{mg} \mathrm{g}^{-1}\right)$ and $b\left(\mathrm{~L} \mathrm{mg}^{-1}\right)$ are empirical constants representing the mono-layer adsorption capacity and the energy of adsorption, respectively, and the plot of $c_{e} / q_{e}$ against $c_{e}$ yields a straight line with the slope $1 / Q$ and the

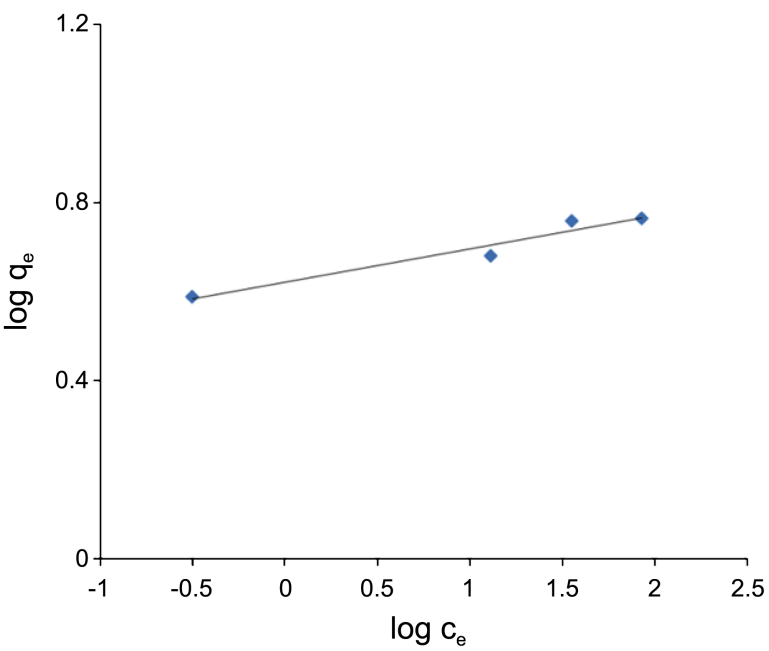

Figure 2. Freundlich adsorption isotherm curve for T-P at $298 \mathrm{~K}$.

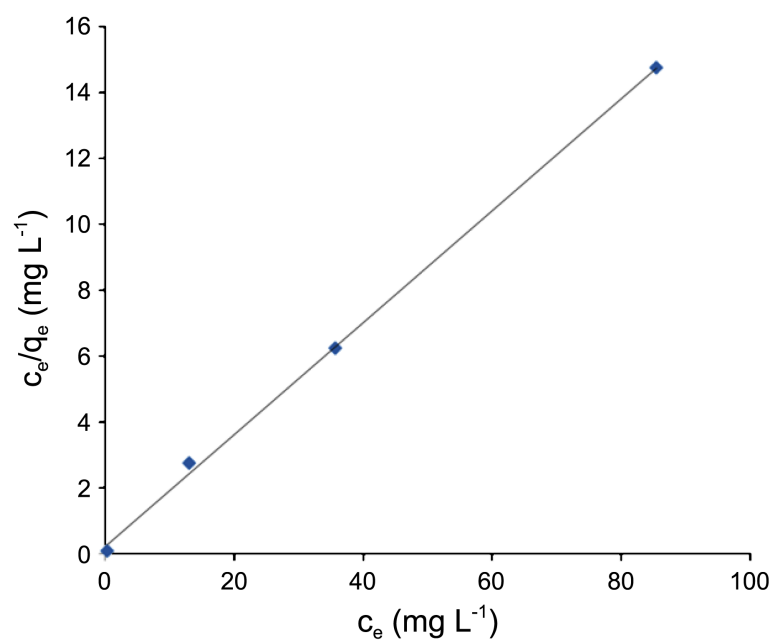

Figure 3. Langmuir adsorption isotherm curve for T-P at $298 \mathrm{~K}$.

\begin{tabular}{|c|c|c|c|c|c|}
\hline \multicolumn{3}{|c|}{ Freundlich constants } & \multicolumn{3}{|c|}{ Langmuir constants } \\
\hline $\begin{array}{c}k_{f} \\
\left(\mathrm{mg} \mathrm{g}^{-1}\right)\end{array}$ & $1 / n$ & $R^{2}$ & $\begin{array}{c}Q \\
\left(\mathrm{mg} \mathrm{g}^{-1}\right)\end{array}$ & $\begin{array}{c}b \\
\left(\mathrm{~L} \mathrm{mg}^{-1}\right)\end{array}$ & $R^{2}$ \\
\hline 4.21 & 0.072 & 0.9465 & 5.82 & 6.313 & 0.999 \\
\hline
\end{tabular}

Table 2. Freundlich and Langmuir constants for adsorption of T-P on loess at $298 \mathrm{~K}$

intercept $1 / Q_{b}$.

The plots of Freundlich and Langmuir isotherm of T-P on loess at $298 \mathrm{~K}$ are presented in Figures 2 and 3, and the corresponding isotherm parameters are listed in Table 2 . It was observed that the experimental data deviates more in case of the Freundlich than Langmuir plot. This is further verified by the correlation coefficient $\left(\mathrm{R}^{2}\right)$ value, shown in Table 2, of the linear plots. It is evident that the Langmuir isotherm fits the experimental data better than the Freundlich isotherm, suggesting the good applicability of the Langmuir model to this adsorption.

The Langmuir adsorption capacity of loess for adsorption of T-P was found to be $5.82 \mathrm{mg} \mathrm{g}^{-1}$. In case of Langmuir isotherm model, the type of adsorption is classified by a dimensionless constant separation factor $r^{18}$ which is given by the following equation:

$$
r=\frac{1}{1+b c_{i}}
$$

Where, $c_{i}\left(\mathrm{mg} \mathrm{L}^{-1}\right)$ is the initial adsorbate concentration. The $r$ values greater than 1 indicate unfavorable type of adsorption while the values between 0 and 1 represent favorable adsorption. In this study, the $r$ values lie within $0.016-0.137$ for initial T-P concentrations. These values reflect that loess favors the adsorption of T-P from solution in the studied concentration range.

Compared with the Langmuir isotherm model, the $R^{2}$ value of Freundlich isotherm model was slightly lower and found to be approximately 0.95 . It can be said that the experimental data for adsorption of T-P can be also adequately described by the Freundlich isotherm model. The 
value of $1 / n$, one of the Freundlich isotherm constants, explains the type of isotherm. When $0<1 / n<1$, the adsorption is favorable. Whereas, when $1 / n>1$, the adsorption is unfavorable. ${ }^{19}$ The value of $1 / n$ obtained from experimental data indicates that T-P is adsorbed favorably by loess.

Adsorption Kinetics. To interpret the adsorption kinetics and the rate-determining step of T-P by loess, the pseudofirst-order, ${ }^{20}$ pseudo-second-order ${ }^{21}$ and intra-particle diffu$\operatorname{sion}^{22}$ kinetic models were employed. These kinetic models are based on the assumption that the rate of adsorption is proportional to the number of free sites, the square of the number of unoccupied sites and the boundary layer thickness, respectively. The conformity between experimental data and the model-predicted values was expressed by the correlation coefficient $R^{2}$. The relatively higher value is more applicable model to the kinetics of T-P adsorption.

The pseudo-first-order kinetic model is given as:

$$
\log \frac{q_{e}}{q_{e}-q_{t}}=\frac{k_{1}}{2.303} t
$$

Eq. (5) can be rearranged to obtain a linear form:

$$
\log \left(q_{e}-q_{t}\right)=\log q_{e}-\frac{k_{1}}{2.303}
$$

Where, $k_{1}\left(\mathrm{~min}^{-1}\right)$ is the equilibrium rate constant of the pseudo-first-order adsorption. The values of $q_{e}$ and $k_{1}$ are determined from the slope and intercept of the straight line.

The pseudo-second-order kinetic model is presented as:

$$
\frac{1}{q_{e}-q_{t}}=\frac{1}{q_{e}}+k_{2}
$$

Eq. (7) can is linearized as:

$$
\frac{t}{q_{t}}=\frac{1}{k_{2} q_{e}^{2}}+\frac{1}{q_{e}}
$$

Where, $k_{2}\left(\mathrm{~g} \mathrm{mg}^{-1} \mathrm{~min}^{-1}\right)$ is the equilibrium rate constant of the pseudo-second-order adsorption. The values of $q_{e}$ and $k_{2}$ are obtained from the slope and intercept of the straight line.

The intra-particle diffusion model is written as:

$$
\log q_{t}=k_{i d} t^{1 / 2}+C
$$

Where, $k_{i d}\left(\mathrm{mg} \mathrm{g}^{-1} \mathrm{~min}^{-1 / 2}\right)$ is the intra-particle diffusion rate constant and $C\left(\mathrm{mg} \mathrm{g}^{-1}\right)$ is the intercept which reflects the boundary layer effect. The values of $k_{i d}$ are determined from the slope and intercept of the straight line.

Figures 4-6 represent the plots of the pseudo-first-order, pseudo-second-order and intra-particle diffusion kinetic models fitting to the experimental data for loess at different initial T-P concentrations. The experimental amounts of adsorption equilibrium $q_{e, \exp }$, the rate constants of corresponding kinetic models $k_{1}, k_{2}$ and $k_{i d}$, the calculated amount of adsorption equilibrium $q_{e, \text { cal }}$ and the correlation coefficients $R^{2}$ are listed in Table 3 .

From Table 3, it was observed that the calculated amounts of adsorption equilibrium $q_{e, \text { cal }}$ from pseudo-second-order kinetic model are relatively similar to the experimental amounts

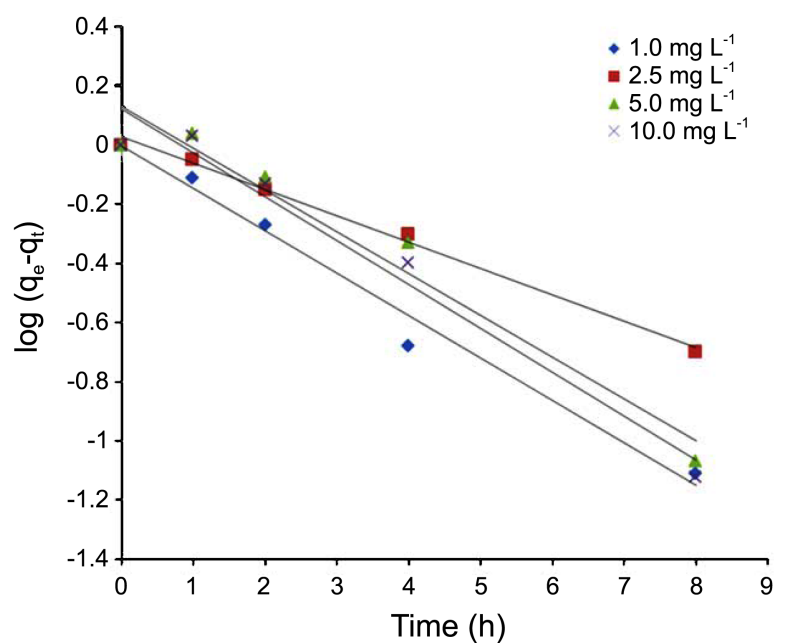

Figure 4. Plots of pseudo-first-order kinetics of T-P adsorption on loess at $298 \mathrm{~K}$.

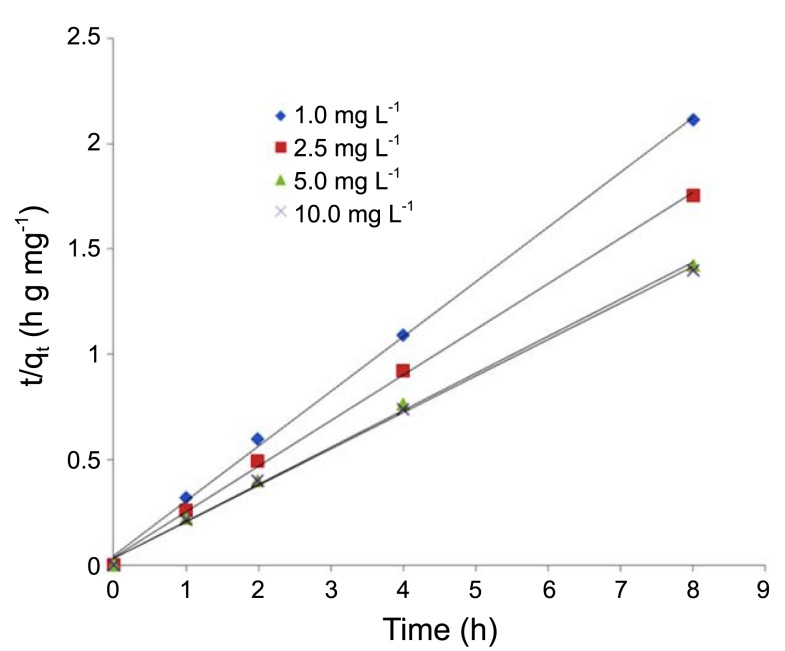

Figure 5. Plots of pseudo-second-order kinetics of T-P adsorption on loess at $298 \mathrm{~K}$.

of adsorption equilibrium $q_{e, \text { exp }}$. Moreover, the pseudosecond-order kinetic model appeared to be the better-fitting model because it has higher $R^{2}$ than those of the pseudosecond-order and intra-particle diffusion kinetic models for loess. The correlation coefficients $R^{2}$ for the pseudo-secondorder kinetic model are very close to 1.0 for all initial T-P concentrations. These results suggest that the T-P adsorption on loess follows the pseudo-second-order kinetic model. Furthermore, the value of pseudo-second-order kinetic rate constant $k_{2}$ depends on the experimental conditions like initial concentration, the $\mathrm{pH}$ of solution and temperature. As a rule, $k_{2}$ decreases with increasing initial adsorbate concentrations. ${ }^{23}$ In this study, the rate constants $k_{2}$ were decreased when increasing the initial T-P concentrations from 1.0 to 2.5, 5.0 and $10.0 \mathrm{mg} \mathrm{L}^{-1}$. It shows that the solution with lower T-P concentration is easy to equilibrate by the loess.

The adsorption process of adsorbates from aqueous solution onto adsorbent generally occurs through three consecutive steps: $:^{24}$ (1) transport of adsorbates from boundary layer to the surface of adsorbent (film diffusion); (2) transport of 
Table 3. Pseudo-first-order, pseudo-second-order and intra-particle diffusion kinetic model parameters for different initial T-P concentration at $298 \mathrm{~K}$

\begin{tabular}{|c|c|c|c|c|c|}
\hline \multirow{2}{*}{ Kinetic model } & \multirow{2}{*}{ Parameters } & \multicolumn{4}{|c|}{ Initial concentration $\left(\mathrm{mg} \mathrm{L}^{-1}\right)$} \\
\hline & & 1.0 & 2.5 & 5.0 & 10.0 \\
\hline \multirow{4}{*}{ Pseudo-first-order } & $q_{\mathrm{e}, \exp }\left(\mathrm{mg} \mathrm{g}^{-1}\right)$ & 3.87 & 4.77 & 5.72 & 5.8 \\
\hline & $q_{\mathrm{e}, \mathrm{cal}}\left(\mathrm{mg} \mathrm{g}^{-1}\right)$ & 9.93 & 19.72 & 5.5 & 28.8 \\
\hline & $k_{1}\left(\mathrm{~h}^{-1}\right)$ & 0.37 & 0.22 & 0.17 & 0.18 \\
\hline & $R^{2}$ & 0.9833 & 0.9939 & 0.9689 & 0.9533 \\
\hline \multirow[t]{3}{*}{ Pseudo-second-order } & $q_{\mathrm{e}, \mathrm{cal}}\left(\mathrm{mg} \mathrm{g}^{-1}\right)$ & 3.62 & 4.25 & 4.99 & 5.17 \\
\hline & $k_{2}\left(\mathrm{~h}^{-1}\right)$ & 1.03 & 0.91 & 0.74 & 0.75 \\
\hline & $R^{2}$ & 0.9986 & 0.9987 & 0.9983 & 0.9981 \\
\hline \multirow[t]{3}{*}{ Intraparticle diffusion } & $C\left(\mathrm{mg} \mathrm{g}^{-1}\right)$ & 2.52 & 3.46 & 4.48 & 4.22 \\
\hline & $k_{\text {id }}\left(\mathrm{mg} \mathrm{g}^{-1} \mathrm{~h}^{-1 / 2}\right)$ & 0.58 & 0.42 & 0.41 & 0.51 \\
\hline & $R^{2}$ & 0.9025 & 0.9899 & 0.9887 & 0.9869 \\
\hline
\end{tabular}

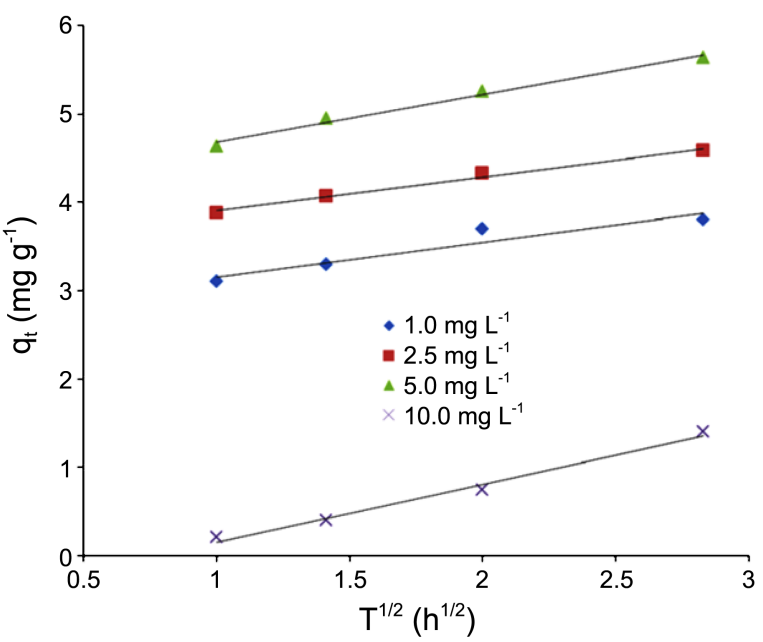

Figure 6. Plots of intra-particle diffusion kinetics of T-P adsorption on loess at $298 \mathrm{~K}$.

adsorbates within the pores of adsorbent (pore or intraparticle diffusion); (3) adsorption of adsorbates on the interior surface of adsorbent. Among three steps, the third step is very fast and does not represent the rate-determining step in the adsorption process. So, the adsorption rate is normally determined by the film and/or intra-particle diffusion steps. ${ }^{25}$ If the plot gives a straight line and pass through the origin, the adsorption process is controlled only by the intra-particle diffusion. On the other hand, if the plot shows multi-linearity or does not pass through the origin, the adsorption process is controlled by two or more diffusion mechanism. ${ }^{19}$ As seen from Figure 6, the plots of $q_{t}$ versus $t_{1 / 2}$ were linear for all initial concentrations and straight lines did not pass through the origin. These results suggest that the adsorption process of T-P onto loess may be controlled by both film and intra-particle diffusion, rather than only film or intra-particle diffusion.

Adsorption Thermodynamics. Adsorption thermodynamics was further studied varying different temperatures $(278,298$ and $323 \mathrm{~K})$ at the selected concentration of $2.5 \mathrm{mg}$ $\mathrm{L}^{-1}$ in order to study the feasibility of the process and ap- plication of the present adsorbents. The respective thermodynamic parameters such as the free energy $\Delta G$, the enthalpy $\Delta H$ and the entropy $\Delta S$ were determined by using the following equations:

$$
\begin{gathered}
K_{d}=\frac{c_{e}}{q_{e}} \\
\Delta G=-R T \ln K_{d} \\
\Delta G=\Delta H-T \Delta S
\end{gathered}
$$

Where, $K_{d}$ is the distribution coefficient $\left(\mathrm{L} \mathrm{g}^{-1}\right)$ for the adsorption and $R$ is the universal gas constant $\left(8.314 \mathrm{~J} \mathrm{~mol}^{-1}\right.$ $\mathrm{K}^{-1}$ ).

The enthalpy $\Delta H$ and entropy $\Delta S$ were evaluated by using the following equation:

$$
R \ln K_{d}=\Delta S-\Delta H \frac{1}{T}
$$

The $\Delta H$ and the $\Delta S$ values were obtained from the slope and the intercept of the straight line.

The results were presented in Table 4. As shown in Table 4, the $\Delta G$ of loess showed the negative values at the studied temperatures. It indicates that the adsorption of T-P on loess is of a fairly favorable and spontaneous process. The $\Delta G$ values decreased from -2.39 to $-2.67 \mathrm{~kJ} \mathrm{~mol}^{-1}$ with increasing temperature, which indicate that the adsorption of T-P on loess is more spontaneous at higher temperatures. It is noted that the $\Delta G$ value, up to $-20 \mathrm{~kJ} \mathrm{~mol}^{-1}$ is indicative of physical adsorption, while more negative than $-40 \mathrm{~kJ} \mathrm{~mol}^{-1}$ indicates chemical adsorption. ${ }^{26}$ Therefore, it is clear that the adsorp-

\begin{tabular}{|c|c|c|c|c|}
\hline \multicolumn{3}{|c|}{$\Delta G\left(\mathrm{~kJ} \mathrm{~mol}^{-1}\right)$} & \multirow{2}{*}{$\begin{array}{c}\Delta H \\
\left(\mathrm{~kJ} \mathrm{~mol}^{-1}\right)\end{array}$} & \multirow{2}{*}{$\begin{array}{c}\Delta S \\
\left(\mathrm{~J} \mathrm{~mol}^{-1} \mathrm{~K}^{-1}\right)\end{array}$} \\
\hline $278 \mathrm{~K}$ & $298 \mathrm{~K}$ & $328 \mathrm{~K}$ & & \\
\hline-2.39 & -2.5 & -2.67 & 0.66 & 10.96 \\
\hline
\end{tabular}
tion of T-P on loess follows the physical adsorption. The magnitude of $\Delta H$ gives information about the adsorption

Table 4. Thermodynamic parameters for T-P adsorption on loess 
mechanism. For physical adsorption, $\Delta H$ is generally less than $80 \mathrm{~kJ} \mathrm{~mol}^{-1}$ while for chemical adsorption the values lie in the range 80 and $400 \mathrm{~kJ} \mathrm{~mol}^{-1} \cdot{ }^{27}$ Typically, the positive value of $\Delta H$ and $\Delta S$ confirms the endothermic nature and the increased randomness for the overall adsorption process, respectively. In this study, the $\Delta H$ and the $\Delta S$ were found to be positive values. These results imply that the adsorption of T-P on loess is endothermic process and is aided by increased randomness at the adsorbent-solution interface.

\section{Conclusion}

The capability of loess for adsorption of T-P and T-N from aqueous solution was evaluated. The observed adsorption data showed that loess is not effective adsorbent for adsorption of T-N. However, loess exhibited much higher adsorption capacity for T-P. The adsorption capacity by loess for T$\mathrm{P}$ was dependant on initial T-P concentrations. At concentration of $1.0 \mathrm{mg} \mathrm{L}^{-1}$, approximately $97 \%$ of T-P adsorption was achieved by loess. The adsorption isotherm study showed that the adsorption of T-P on loess follows the Langmuir isotherm model due to the higher $R^{2}$ value than the Freundlich isotherm model. The adsorption kinetics was more appropriately described by the pseudo-second-order model rather than pseudo-first-order and intra-particle diffusion model. The calculated negative values of $\Delta G$ reflect that the adsorption of T-P on loess is a favorable and spontaneous process. The positive value of $\Delta H$ indicates that the adsorption is the endothermic in nature. Moreover, the positive $\Delta S$ value obtained also illustrates the increased randomness at the adsorbent-solution interface.

Acknowledgments. This work was supported by the National Research Foundation of Korea(NRF) Grant funded by the Korean Government (MOE) (No. 2013R1A1A2013257).

\section{References}

1. Ryu, H.; Lee, S. J. KSEE 2005, 27(2), 206-214.

2. Yang, J.; Wang, S.; Lu, Z.; Lou, S. J. Hazard. Mater. 2009, 168,
331-337.

3. Lee, Y.; Yoo, S.; Oh, D.; Lee, Y. J. KSEE 2010, 32(10), 949-956.

4. Awual, M. R.; Jyo, A. Desalination 2011, 281, 111-117.

5. Huang, B.; Feng, H.; Wang, M.; Li, N.; Cong, Y.; Shen, D. Bioresource Technology 2013, 132, 91-98.

6. Zhang, G.; Zhang, H.; Zhang, C.; Zhang, G.; Yang, F.; Yuan, G.; Gao, F. Process Biochemistry 2013, 48, 893-900.

7. Hong, S. T.; Lee, J.; Hong, H. P.; Yoo, S.; Lim, J. S.; Yoo, K.; Park, H. S. Korean Chem. Eng. Res. 2007, 45(2), 160-165.

8. Choi, J.; Lee, S.; Park, K.; Lee, K.; Kim, K.; Kim, D.; Lee, S. Desalination 2011, 266, 281-285.

9. Littler, J.; Geroni, J. N.; Sapsford, D. J.; Coulton, R.; Griffiths, A. J. Chemosphere 2013, 90, 1533-1538.

10. Seo, J. B.; Yoon, C. H.; Rim, Y. T.; Cho, K. M. J. Korean Soc. Water Qual. 1994, 10, 421-426.

11. Brooks, A. S.; Rozenwald, M. N.; Geohring, L. D.; Lion, L. W.; Steenhuis, T. S. Ecol. Eng. 2000, 15, 121-132.

12. Ozacar, M. Chemosphere 2003, 51, 321-327.

13. Karaca, S.; Gurses, A.; Ejder, M.; Aclkylldlz, M. J. Hazard. Mater. 2006, B128, 273-279.

14. Karageorgiou, K.; Paschalis, M.; Anastassakis, G. N. J. Hazard. Mater. 2007, 139, 447-452.

15. Kamiyango, M. W.; Masamba, S. M. I.; Fabiano, S. E. Malawi Phys. Chem. Earth 2009, 34, 850-856.

16. Mohanthy, K.; Naidu, J. T.; Meikap, B. C.; Biawas, M. N. Ind. Eng. Chem. Res. 2006, 45, 5165-5171.

17. Nadaroglu, H.; Kalkan, E.; Demir, N. Desalination 2010, 251, 90 95.

18. Palanisamy, P. N.; Sivakumar, P. Desalination 2009, 249, 388397.

19. Vasiliu, S.; Bunia, I.; Racovita, S.; Neagu, V. Carbohydr. Polym. 2011, 85(2), 376-387.

20. Lagergren, S. Kungl. Svenska Vetenskapsakademien Handlinger Band 1898, 24, 1-39.

21. Ho, Y. S.; Mckay, G. Can. J. Chem. Eng. 1998, 76(4), 822-827.

22. Weber, W. J.; Morris, J. C. J. Sanitary Eng. Div., Am. Civil Eng. 1963, 89, 31-39.

23. Salam, M. A.; Al-Zhrani, G.; Kosa, S. A. C. R. Chimie 2012, 15, 398-408.

24. Yousef, R. I.; El-Eswed, B.; Al-Muhtaseb, A. H. Chem. Eng. J. 2011, 171, 1143-1149.

25. Sun, C. M.; Zhang, G. H.; Qu, R. J.; Yu, Y. Chem. Eng. J. 2011, 170, 250-257.

26. Khani, M. H. Environ. Sci. Pollu. Res. 2011, 18, 1593-1605.

27. Nollet, H.; Roels, M.; Lutgen, P.; Van der Meeren, P.; Verstraete, W. Chemosphere 2003, 534, 655-665. 